\title{
Obstetric outcome after fetal reduction to singleton pregnancies
}

\author{
L. De Catte* and W. Foulon \\ Unit of Feto-Maternal Medicine, Department of Obstetrics and Gynecology, University Hospital Vrije Universiteit Brussel, \\ Brussels, Belgium
}

\begin{abstract}
Objective To study the outcome after fetal reduction or selective termination to singleton pregnancies for various indications.

Methods Fetal reduction or selective feticide to singleton pregnancies was performed in 80 multiple gestations (congenital malformations, 17 cases; high-risk obstetric conditions, 25 cases; or social/ psychological indications, 38 cases).

Results The overall pregnancy loss rate was $10 \%$; however, pregnancy failure was significantly higher in selective reductions performed for preterm prelabor rupture of membranes (PPROM) (4/8) compared with monochorionic twin and bad obstetric history. Fetal reduction to singletons for psychological reasons resulted in a pregnancy wastage of 5.3\% (2/38). Procedures performed at $\leqslant 14$ weeks showed a significantly lower fetal loss rate $(2 / 61 ; 3.3 \%)$, a higher mean gestational age at delivery $(38.3 \pm 2.2$ weeks), and a decreased prematurity rate $(p \leqslant 0.001)$. The number of reduced fetuses, prenatal diagnosis by chorionic villus sampling before the reduction and maternal age did not interfere with pregnancy outcome.
\end{abstract}

Conclusion Fetal reduction to singleton pregnancies has a favorable outcome, especially when performed before 14 weeks of gestation. Copyright (C) 2002 John Wiley \& Sons, Ltd.

KEY WORDS: congenital malformation; fetal reduction; multiple pregnancy; selective termination

\section{INTRODUCTION}

The reduction to a single fetus is appropriate in twin pregnancies with structural or genetic fetal abnormalities, uterine malformations or significant medical disease (Evans et al., 1998). Twin gestations complicated by a single anomalous fetus showed a significantly lower gestational age at delivery and birth weight, and a higher rate of perinatal mortality and caesarian delivery, than normal twin pregnancies (Malone et al., 1996). Late elective termination of abnormal fetuses in twin pregnancies has been associated with favorable perinatal outcome of the healthy twin in several studies (Lipitz et al., 1996, 1997; Berkowitz et al., 1997; Evans et al., 1999a). However it is not clear whether the obstetric advantage of selective termination is applicable to all fetal malformations. Favorable outcome for the unaffected twin without selective termination of the affected fetus has been reported for twin pregnancies with anencephaly (Lipitz et al., 1995; Sebire et al., 1997a) or lethal chromosomal abnormalities (Sebire et al., 1997b). Other commonly accepted indications of elective fetal reduction are those to improve pregnancy outcome as in patients with cervical incompetence, uterine malformations (Ginsberg et al., 1997) or a history of repetitive preterm delivery. Fetal reduction to a singleton for social/psychological indications remains controversial and is not widely performed (Evans et al., 1998).

\footnotetext{
*Correspondence to: L. De Catte, Department of Obstetrics and Gynecology, Feto-Maternal Medicine, AZ VUB, Laarbeeklaan 101, 1090 Brussels, Belgium. E-mail: luc.decatte@az.vub.ac.be
}

The present study evaluates the obstetric outcome after multifetal pregnancy reduction (MFR) or selective feticide (SF) to singleton pregnancies in various clinical conditions.

\section{PATIENTS AND METHODS}

The present prospective study is of 84 consecutive patients in which MFR or SF to singleton pregnancies was performed. Four pregnancies were excluded from further analysis because of incomplete data. Of the 80 pregnancies studied, eight were quadruplet, 27 were triplet and 45 were twin pregnancies.

Under local anesthesia and sonographic guidance, potassium chloride $(\mathrm{KCl})(1 \mathrm{mEq} / \mathrm{ml})$ was injected with a 22-gauge spinal needle into the fetal thorax near to or into the fetal heart. In monochorionic twin pregnancies, both fetuses were reduced by needling each fetus separately. The procedure was considered successful after a fetal asystole of $2 \mathrm{~min}$ and the needle was redrawn. The patients were divided into three major groups: pregnancies complicated by the presence of a congenital malformation in one of the fetuses (Group I); pregnancies with high-risk obstetric conditions (Group II) and multiple pregnancies reduced for social/psychological indications (Group III).

Prenatal diagnosis was mainly performed by chorionic villus sampling (CVS). The technical aspects were as described previously (De Catte et al., 1998a). Later in the second trimester, amniocentesis or fetal blood sampling was used for rapid fetal karyotyping.

Perinatal outcome was collected for all completed 
pregnancies. Pregnancy loss at $<500$ g or $\leqslant 22$ weeks of gestation was described as early fetal loss or spontaneous miscarriage. Fetal mortality rates included fetuses of $>500 \mathrm{~g}$ or fetal death occurring after 22 weeks of gestation, according to the definitions of the World Health Organization (WHO) and Fédération Internationale de Gynécologie et Obstétrique (FIGO) criteria. For the purpose of the present study, fetal loss rate was the sum of early fetal loss and fetal death. Mean gestational age at delivery, mean birth weight and prematurity rates were calculated on all pregnancies evolving beyond 22 weeks.

All statistical tests were performed two-sided at a $5 \%$ level of significance. To investigate the influence of the indication for the procedure, the gestational age at the time of the reduction, the number of fetuses reduced, and the performance of a CVS on the pregnancy loss rate and on preterm delivery, Fisher exact tests (FE) were used for each variable separately. The effect of maternal age on pregnancy outcome was investigated by means of the non-parametric MannWhitney test (MW). The influence of the above factors on the gestational age at delivery and the birth weight was investigated by means of Kruskall-Wallis $(\mathrm{KW})$ or Mann-Whitney tests for each categorical factor and by means of a Spearman rank correlation coefficient for maternal age. Finally, stepwise regression was performed to predict the mean gestational age at delivery and the mean birth weight by each of the possible prognostic factors, with a $10 \%$ level of significance to decide whether or not to include a variable.

\section{RESULTS}

MFR or SF to singletons was performed in 80 consecutive multiple pregnancies at a mean gestational age of $13.0 \pm 3.3$ weeks. Sixty-one procedures were carried out at 14 weeks or less $(76.3 \%)$. The mean maternal age was $31.7 \pm 4.2$ years. Twenty-two patients $(27.5 \%)$ were 35 years old or over.

In Group I, fetal reductions were performed for either chromosomal abnormalities (eight) or for structural defects (nine) in 17 twin pregnancies. Group II consisted of 25 high-risk obstetric patients. There was a monochorionic twin pregnancy as a part of the multiple gestation in ten cases; eight patients showed a premature rupture of membranes before 20 weeks of gestation and another seven had a bad obstetric history. In Group III, 38 patients had a reduction to a singleton pregnancy for psychological reasons. In 45 twin pregnancies one fetus was reduced. Of the remaining 35 pregnancies, two fetuses were reduced in 27 cases, and three fetuses in eight cases. Prenatal diagnosis by CVS before fetal reduction was performed in 30 patients at a mean gestational age of $11.7 \pm 1.9$ weeks (range 10.0-18.7 weeks). Twenty-one patients were sampled for increased risk of fetal aneuploidy, of whom 15 for advanced maternal age $\geqslant 35$ years, two for ICSI, and four for congenital malformations. In eight additional cases, chorionic villi were retrieved for psychological reasons, and in one case for fetal growth discordance.

Spontaneous early or late fetal loss occurred in $8 / 80(10 \%)$ reduced pregnancies (Table 1$)$. Early fetal demise was observed in $5 / 8$ pregnancies $(62.5 \%)$, one of which was attributed to a congenital cytomegalovirus (CMV) infection. The remaining three fetal deaths occurred between 22 and 28 weeks of gestation. In one pregnancy with congenital malformation, anhydramnion led to the misjudgment of chorionicity resulting in the death of the co-twin after $\mathrm{KCl}$ injection. Unfortunately there was no first trimester ultrasound to state chorionicity in this patient. The correction of fetal loss rate, taking these facts into consideration, would be reduced to $7.5 \%$. One additional neonatal loss was encountered because of extreme preterm delivery.

Table 1 -Fetal loss after reduction to singleton pregnancies in relation to the indication of the procedure, the gestational age at reduction, the number of fetuses reduced, and the performance of a CVS before the reduction process

\begin{tabular}{|c|c|c|c|c|c|c|c|}
\hline & \multicolumn{2}{|l|}{ Group I } & \multicolumn{3}{|l|}{ Group II } & \multirow{2}{*}{$\begin{array}{l}\text { Group III } \\
\begin{array}{l}\text { Social- } \\
\text { psychological }\end{array}\end{array}$} & \multirow[b]{2}{*}{ Total $(\%)$} \\
\hline & $\begin{array}{l}\text { Chromosome } \\
\text { abnormality }\end{array}$ & $\begin{array}{l}\text { Structural } \\
\text { defect }\end{array}$ & $\begin{array}{l}\text { Monochorionic } \\
\text { multiplets }\end{array}$ & PPROM & $\begin{array}{l}\text { Obstetric } \\
\text { history }\end{array}$ & & \\
\hline$\leqslant 14$ weeks & 6 & - & 10 & 1 & 7 & 37 & $61(76.3)$ \\
\hline Fetal loss & 0 & - & 0 & 0 & 0 & 2 & $2 *(3.3)$ \\
\hline$>14$ weeks & 2 & 9 & - & 7 & - & 1 & $19(23.7)$ \\
\hline Fetal loss & 0 & 2 & - & 4 & - & 0 & $6^{*}(31.6)$ \\
\hline 1 fetus reduced & 8 & 9 & - & 8 & - & 20 & $45(56.3)$ \\
\hline Fetal loss & 0 & 2 & - & 4 & - & 0 & $6 * *(13.3)$ \\
\hline$>1$ fetus reduced & - & - & 10 & - & 7 & 18 & $35(43.7)$ \\
\hline Fetal loss & - & - & 0 & - & 0 & 2 & $2 * *(5.7)$ \\
\hline CVS & 7 & 3 & 2 & 2 & 2 & 14 & $30(37.5)$ \\
\hline Fetal loss & 0 & 1 & 0 & 0 & 0 & 1 & $2^{\dagger}(6.7)$ \\
\hline No CVS & 1 & 6 & 8 & 6 & 5 & 24 & $50(62.5)$ \\
\hline Fetal loss & 0 & 1 & 0 & 4 & 0 & 1 & $6^{\dagger}(12.0)$ \\
\hline
\end{tabular}

$* p=0.001, * * p=0.455,{ }^{\dagger} p=0.703$

CVS, Chorionic villus sampling; PPROM, preterm prelabor rupture of membranes. 
There was no significant difference in fetal loss according to the three major groups of indication (FE: $p=0.393$ ). In Group II however, four late pregnancy losses occurred among those pregnancies complicated by early preterm prelabor rupture of membranes (PPROM), compared with none in the two other subgroups (FE: $p=0.008$ ) (Table 2). There was a significantly lower pregnancy loss rate associated with fetal reductions performed at $\leqslant 14$ weeks $(2 / 61 ; 3.3 \%)$ compared with reductions performed at a later gestational age $(6 / 19 ; 31.6 \%)$ (FE: $p=0.001)$. The number of fetuses reduced $(1$ or $>1)$, the performance of a CVS before the reduction or advanced maternal age did not significantly alter the pregnancy loss (FE: $p=0.455,0.703$ and 0.930 , respectively). Reduction of one fetus in 45 patients resulted in six pregnancy losses (13.3\%), four of which were attributed to the PPROM group. Fetal reduction of more than one fetus in the remaining 35 cases was associated with two pregnancy losses $(5.7 \%)$. A total of $2 / 30$ pregnancies $(6.7 \%)$ undergoing a CVS before the reduction were lost, compared with $6 / 50(12 \%)$ in the group where prenatal diagnosis was not carried out.

The mean gestational age at delivery in 75 pregnancies evolving beyond 22 weeks of gestation was $37.3 \pm 3.7$ weeks (range 23-41 weeks) (Table 3 ). There was no difference in mean gestational age at delivery in relation to the main indication categories. However, the mean gestational age at delivery after fetal reduction for chromosomal malformations was $38.9 \pm 1.4$ weeks and significantly higher than the $33.1 \pm 6.0$ weeks for cases with structural defects (MW: $p=0.010$ ) (Table 2). In Group II (fetal reductions for high-risk obstetric conditions) a significantly different mean gestational age at delivery was observed according to the subgroup. Reduction of the monochorionic twin pregnancy, selective feticide of the anhydramnic twin fetus after PPROM and fetal reduction for high-risk obstetric history showed a mean gestational age at delivery of $39.2 \pm 1.0$ weeks, $32.8 \pm 5.2$ weeks and $37.8 \pm 0.9$ weeks (KW: $p=0.003$ ), respectively. The mean gestational age at delivery was $38.3 \pm 2.2$ weeks when fetal reduction was performed at $\leqslant 14$ weeks, compared with $33.9 \pm 5.5$ weeks for interventions after 14 weeks (KW: $p<0.001$ ). The number of reduced fetuses, the performance of a CVS before the reduction and maternal age did not significantly interfere with the gestational age at delivery $(p=0.487,0.725$ and 0.614 , respectively). Twenty-five patients delivered at or before 37 completed weeks (33\%). Preterm delivery occurred significantly more often after fetal reduction for structural defects (7/9) than for chromosomal malformations (1/8) (FE: $p=0.015)$, and significantly more frequently in patients with selective feticide for PPROM (4/5) than for other high-risk obstetric events $(3 / 16)(\mathrm{FE}: p=0.004)$.

Table 2-Detailed analysis of the pregnancy outcome in the subgroups

\begin{tabular}{|c|c|c|c|c|c|c|c|c|}
\hline & $\begin{array}{l}\text { Fetal } \\
\text { loss }\end{array}$ & $p$ & $\begin{array}{l}\text { Mean } \mathrm{GA} \pm \mathrm{SD} \\
\text { at delivery (weeks) }\end{array}$ & $p$ & $\begin{array}{l}\text { Mean } \mathrm{BW} \pm \mathrm{SD} \\
\text { at delivery }(\mathrm{g})\end{array}$ & $p$ & $\begin{array}{l}\text { Preterm } \\
\text { delivery (\%) }\end{array}$ & $p$ \\
\hline Structural defects & $2 / 9$ & 0.471 & $33.1 \pm 6.0$ & 0.010 & $2504 \pm 892$ & 0.148 & $7 / 9(78)$ & 0.015 \\
\hline Chromosomal abnormalities & $0 / 8$ & & $38.9 \pm 1.4$ & & $3299 \pm 744$ & & $1 / 8(12.5)$ & \\
\hline Dichorial triplet & $0 / 10$ & & $39.2 \pm 1.0$ & & $3143 \pm 418$ & & $0 / 9$ & \\
\hline PPROM & $4 / 8$ & 0.008 & $32.8 \pm 5.2$ & 0.003 & $2428 \pm 605$ & 0.08 & $4 / 5(80)$ & 0.004 \\
\hline High-risk history & $0 / 7$ & & $37.8 \pm 0.9$ & & $2843 \pm 394$ & & $3 / 7(43)$ & \\
\hline
\end{tabular}

GA, Gestational age; BW, birth weight; PPROM, preterm prelabor rupture of membranes.

Table 3-Mean gestational age (GA) at delivery and mean birth weight (BW) after reduction to singleton pregnancies in each group, the GA at reduction, the number of fetuses reduced and the performance of a CVS

\begin{tabular}{|c|c|c|c|c|c|}
\hline & $n^{\mathrm{a}}$ & $\begin{array}{l}\text { Mean GA } \pm \text { SD } \\
\text { at delivery (weeks) }\end{array}$ & $p$ & Mean BW \pm SD $(\mathrm{g})$ & $p$ \\
\hline \multicolumn{6}{|l|}{ Indication } \\
\hline Group I & 17 & $35.8 \pm 5.3$ & \multirow{3}{*}{0.218} & $2875 \pm 897$ & \multirow{4}{*}{0.965} \\
\hline Group II & 21 & $37.2 \pm 3.6$ & & $2897 \pm 512$ & \\
\hline Group III & 34 & $38.1 \pm 2.6$ & & $2895 \pm 668$ & \\
\hline GA & & & & & \\
\hline$\leqslant 14$ weeks & 56 & $38.3 \pm 2.2$ & \multirow[t]{2}{*}{$<0.001$} & $2964 \pm 653$ & \multirow[t]{2}{*}{0.094} \\
\hline$>14$ weeks & 16 & $33.9 \pm 5.5$ & & $2610 \pm 718$ & \\
\hline \multicolumn{6}{|c|}{ Fetuses reduced } \\
\hline 1 & 40 & $36.8 \pm 4.4$ & \multirow[t]{3}{*}{0.487} & $2931 \pm 742$ & \multirow[t]{3}{*}{0.592} \\
\hline$>1$ & 32 & $38.0 \pm 2.5$ & & $2844 \pm 599$ & \\
\hline \multicolumn{4}{|l|}{ CVS } & & \\
\hline Yes & 28 & $37.6 \pm 3.5$ & \multirow[t]{2}{*}{0.725} & $2876 \pm 725$ & \multirow[t]{2}{*}{0.880} \\
\hline No & 44 & $37.1 \pm 3.9$ & & $2901 \pm 652$ & \\
\hline
\end{tabular}

${ }^{\mathrm{a} N u m b e r}$ of pregnancies after exclusion of early pregnancy losses ( $\leqslant 22$ weeks). 
The mean birth weight was $2891 \pm 677 \mathrm{~g}$ (range $600-4800 \mathrm{~g}$ ). Although not statistically significant, a trend towards higher birth weights was observed when the fetal reduction was performed $\leqslant 14$ weeks $(2964 \pm 653 \mathrm{~g})$ than $>14$ weeks $(2610 \pm 718 \mathrm{~g})(\mathrm{KW}$ : $p=0.094)$. There was no correlation between the mean birth weight and the indication for the fetal reduction, the number of fetuses reduced, first trimester prenatal diagnosis by CVS or maternal age.

Fitting stepwise models on the mean gestational age and birth weight at delivery revealed that gestational age at reduction is the single most significant factor on pregnancy outcome and confirmed the previous findings for each factor independently.

\section{DISCUSSION}

Pregnancy outcome after fetal reduction or selective termination has been documented by the collaborative series of the world's largest centers (Evans et al., 1998, 1999b). More recently, the international experience on selective termination for structural defects, chromosomal malformations or Mendelian disorders in 402 multiple pregnancies showed pregnancy loss had decreased to $8.2 \%$ (Evans et al., 1999a).

Loss rates after fetal reduction to singleton pregnancies in the present study was $10 \%$. Five of the eight losses occurred before 22 weeks of gestation. One pregnancy was lost because of a first trimester congenital CMV infection. No difference in fetal loss was observed in the three categories of patients. However, looking into the 25 high-risk pregnancies (Group II), a significant difference in pregnancy failure emerged. Four of the eight pregnancies with early second trimester PPROM were lost within 3 weeks of the procedure because of a chorioamnionitis. In one of these cases, the PPROM occurred after a cerclage for a history of cervical incompetence in a twin pregnancy. In our hands, this indication for SF still carries the highest risk of pregnancy failure and preterm delivery. Nevertheless, selective feticide of the anhydramnic fetus in multiple pregnancies complicated by a previable rupture of the membranes (Dorfman et al., 1995; De Catte et al., 1998b; Debbs et al., 1999) has improved fetal outcome by reducing the likelihood of chorioamnionitis, increasing the number of days to delivery, and also raising the survival rate of the healthy co-fetus(es). In the remaining 17 cases, no pregnancies were lost. Among these patients, there were ten dichorionic triplet pregnancies. Monochorionic twin pregnancies carry a six-fold higher fetal loss, a two-fold increase in very preterm delivery (Sebire et al., 1997c) and a 15-20\% risk of twin-twin transfusion syndrome (TTTS). Therefore, if MFR is performed in dichorionic triplet pregnancies, reduction of the monochorionic twin pregnancy should be advised. In the ten cases performed in the present study, no additional losses or obstetric complications were noticed. Unfortunately, none of the patients had been correctly informed about the chorionicity and its related problems at the time of the referral.
Of the thirty-eight (47.5\%) reductions performed for psychological reasons, only two were lost $(5.3 \%)$. Fetal reduction to singleton pregnancies for social reasons seems a relatively safe procedure. Although MFR to singletons for psychological reasons is a policy not widely accepted, we are convinced that couples with social, financial or relationship problems might benefit from this procedure. Some ethical parallels may be drawn with first trimester termination of pregnancy for the same problems. In addition, patients suffering from longstanding primary subfertility may feel unable to cope with their multiple pregnancies and, despite being advised against it, decide to terminate their pregnancies (Marcus and Brinsden, 2000). Moreover, older couples are more inclined to want reduction to singleton gestation (Evans et al., 1997), thereby reducing some problems to parenthood in their $60 \mathrm{~s}$ and 70s. On each occasion, individual psychological and social counseling should facilitate the decisionmaking process.

The gestational age at which the procedure was performed was the single most important factor determining fetal loss after reduction to singleton pregnancies. Performing the MFR/SF before the 15 th week of gestation led to a successful pregnancy outcome in all but two patients $(96.7 \%)$, of which one was related to a congenital CMV infection. Procedures performed after 14 completed weeks resulted in a significantly higher pregnancy failure rate $(31.6 \% ; p=0.001)$. This observation was previously found by other authors (Lynch et al., 1996; Evans et al., 1999a) and was considered as a strong argument to improve prenatal detection of congenital malformations in the first trimester. Compiled data (Evans et al., 1999a) on selective feticide for congenital malformations in 402 multiple pregnancies demonstrated a progressive rise in fetal loss $(\geqslant 24$ weeks) in relation to the gestational age at which the procedure was performed: $5.4 \%, 8.7 \%, 6.8 \%$ and $9.1 \%$ for procedures carried out between 9 and 12, 13 and 18,19 and 24 and $\geqslant 25$ weeks respectively. In a 10-year overview, Yaron et al. (1998) observed a slightly higher fetal loss for fetal reductions performed before 14 weeks, which he attributed to a higher than expected rate of spontaneous abortions in the first trimester. Berkowitz and co-workers (1997) demonstrated that selective feticide for congenital malformations in 100 consecutive cases was accompanied by a low spontaneous loss rate of $3 \%$, and resulted in the birth of healthy infants at or near term in the vast majority of cases. In addition, with increasing experience the discrepancy between fetal loss rates after first and second trimester interventions has decreased (Evans et al., 1999b).

In his collaborative study on multifetal pregnancy reduction, Evans observed higher fetal loss rates (Evans et al., 1998, 1999b) associated with higher starting and finishing numbers of fetuses. Fetal reduction to a singleton pregnancy showed a $13.7 \%$ risk of pregnancy loss (Evans et al., 1998) compared with 10\% in the present series. Procedures performed in twin pregnancies only resulted in $13.3 \%$ pregnancy loss, which seems higher than $9.0 \%$ or $7.9 \%$ in 111 and 
345 twin pregnancies, respectively, reported by Evans. Some of this discrepancy can be explained by the difference in indication for the fetal reduction. Excluding PPROM as an indication for selective feticide from the present data would yield a fetal loss rate of $2 / 37$ or $5.4 \%$ in twin pregnancies. Increasing starting numbers and numbers of fetuses to reduce did not interfere with the pregnancy loss rate in the present data. Only two pregnancies were lost out of 35 triplet and quadruplet gestations (5.7\%). However, this observation could be related to the small number of patients in the present study or to the fact that these procedures were predominantly performed in the first trimester.

Mean gestational ages at delivery and mean birth weights after fetal reduction in the present series were smaller than in low-risk singleton pregnancies, but slightly better than in twin pregnancies. The present data fit with those reported for FR/ST to singleton pregnancies by Lynch (1996), Evans (1999a) and Berkowitz (1997). However, multiple pregnancies with vanishing embryos resulting in singletons tend to do better (mean gestational age: 39.1 weeks; mean birth weight: $3122 \mathrm{~g}$ ) (Manzur et al., 1995). Fetal reduction after 14 weeks significantly reduces mean gestational age at delivery. This observation was shared by Yaron et al. (1998), who reported a decrease of 3 weeks in mean gestational age at delivery and a mean drop of $700 \mathrm{~g}$ in birth weight.

Fetal reduction to singleton pregnancies implies an acceptable low risk of fetal loss, and a near to normal obstetric outcome in terms of gestational age at delivery and mean birth weight. Selective termination in multiple pregnancies with congenital malformations produces a better obstetric prognosis. Fetal reduction for psychological reasons remains a controversial issue, but carries a very low risk of pregnancy failure. We are convinced that in selected couples there are more benefits from fetal reductions in twin pregnancies than perinatal outcome.

\section{ACKNOWLEDGEMENT}

The authors wish to thank $\mathrm{N}$. Verbruggen for her statistical expertise.

\section{REFERENCES}

Berkowitz RL, Stone JL, Eddleman KA. 1997. One hundred consecutive cases of selective termination of an abnormal fetus in a multifetal gestation. Obstet Gynecol 90: 606-610.

De Catte L, Camus M, Bonduelle M, Liebaers I, Foulon W. 1998a.
Prenatal diagnosis by chorionic villus sampling in multiple pregnancies prior to fetal reduction. Am J Perinatol 15: 339-343. De Catte L, Laubach M, Bougatef A, Mares C. 1998b. Selective feticide in twin pregnancies with very early preterm premature rupture of membranes. Am J Perinatol 15: 149-153.

Debbs R, Daly S, Toosa J, Wapner R, Davis G, Weiner S. 1999. Selective termination versus expectant management of premature rupture of membranes in multifetal gestations. Am J Obstet Gynecol 180: S96.

Dorfman SA, Robins RM, Jewell WH, Louis LS, Evans MI. 1995. Second trimester selective termination of a twin with ruptured membranes: elimination of fluid leakage and preservation of pregnancy. Fetal Diagn Ther 10: 186-188.

Evans MI, Hume RF Jr, Polak S, et al. 1997. The geriatric gravida: multifetal pregnancy reduction, donor eggs, and aggressive infertility treatments. Am J Obstet Gynecol 177: 875-878.

Evans MI, Kramer RL, Yaron Y, Drugan A, Johnson MP. 1998. What are the ethical and technical problems associated with multifetal pregnancy reduction? Clin Obstet Gynecol 41: 46-54.

Evans MI, Goldberg JD, Horenstein J, et al. 1999a. Selective termination for structural, chromosomal, and Mendelian anomalies: international experience. Am J Obstet Gynecol 181: 893-897.

Evans M, Wapner R, Carpenter R, et al. 1999b. International collaboration on multifetal pregnancy reduction (MFPR): dramatically improved outcome with increased experience. Am J Obstet Gynecol 180: S66.

Ginsberg NA, Strom C, Verlinsky Y. 1997. Management of a triplet gestation complicated by uterus didelphys. Fetal Diagn Ther 12: $59-60$.

Lipitz S, Meizner I, Yagel S, Shapiro I, Achiron R, Schiff E. 1995. Expectant management of twin pregnancies discordant for anencephaly. Obstet Gynecol 86: 969-72.

Lipitz S, Shalev E, Meizner I, et al. 1996. Late selective termination of fetal abnormalities in twin pregnancies: a multicentre report. $\mathrm{Br}$ J Obstet Gynaecol 103: 1212-1216.

Lipitz S, Peltz R, Achiron R, Barkai G, Mashiach S, Schiff E. 1997. Selective second-trimester termination of an abnormal fetus in twin pregnancies. J Perinatol 17: 301-04.

Lynch L, Berkowitz RL, Stone J, Alvarez M, Lapinski R. 1996. Preterm delivery after selective termination in twin pregnancies. Obstet Gynecol 87: 366-369.

Malone FD, Craigo SD, Chelmow D, D’Alton ME. 1996. Outcome of twin gestations complicated by a single anomalous fetus. Obstet Gynecol 88: 1-5.

Manzur A, Goldsman MP, Stone SC, Frederick JL, Balmaceda JP, Asch RH. 1995. Outcome of triplet pregnancies after assisted reproductive techniques: how frequent are the vanishing embryos? Fertil Steril 63: 252-257.

Marcus SF, Brinsden PR. 2000. Termination of pregnancy after conception with donor oocytes and donor spermatozoa: case report. Hum Reprod 15: 719-722.

Sebire NJ, Sepulveda W, Hughes KS, Noble P, Nicolaides KH. 1997a. Management of twin pregnancies discordant for anencephaly. Br J Obstet Gynaecol 104: 216-219.

Sebire NJ, Snijders RJ, Santiago C, Papapanagiotou G, Nicolaides KH. 1997b. Management of twin pregnancies with fetal trisomies. Br J Obstet Gynaecol 104: 220-222.

Sebire NJ, Snijders RJM, Hughes K, Sepulveda W, Nicolaides K. $1997 \mathrm{c}$. The hidden mortality of monochorionic twin pregnancies. Br J Obstet Gynaecol 104: 1203-1207.

Yaron Y, Johnson KD, Bryant-Greenwood PK, Kramer RL, Johnson MP, Evans MI. 1998. Selective termination and elective reduction in twin pregnancies: 10 years experience at a single centre. Hum Reprod 13: 2301-2304. 